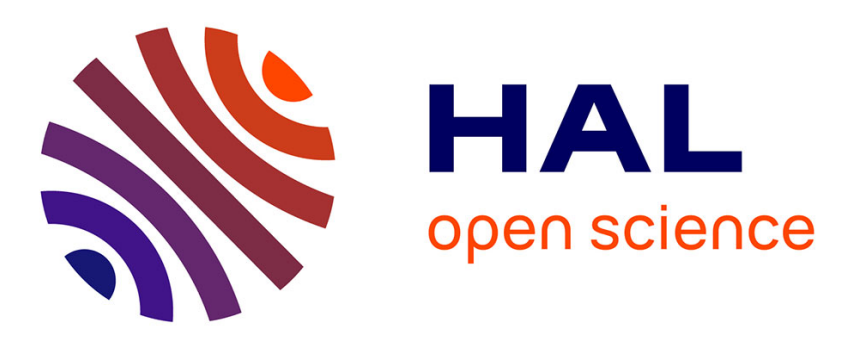

\title{
Evaluation of photosynthetic electrons derivation by exogenous redox mediators
}

Guillaume Longatte, Han-Yi Fu, Olivier Buriez, Eric Labbé, Francis-André

Wollman, Christian Amatore, Fabrice Rappaport, Manon Guille-Collignon, Frédéric Lemaître

\section{To cite this version:}

Guillaume Longatte, Han-Yi Fu, Olivier Buriez, Eric Labbé, Francis-André Wollman, et al.. Evaluation of photosynthetic electrons derivation by exogenous redox mediators. Biophysical Chemistry, 2015, 205, pp.1-8. 10.1016/j.bpc.2015.05.003 . hal-01154581

\section{HAL Id: hal-01154581 https: / hal.sorbonne-universite.fr/hal-01154581}

Submitted on 22 May 2015

HAL is a multi-disciplinary open access archive for the deposit and dissemination of scientific research documents, whether they are published or not. The documents may come from teaching and research institutions in France or abroad, or from public or private research centers.
L'archive ouverte pluridisciplinaire HAL, est destinée au dépôt et à la diffusion de documents scientifiques de niveau recherche, publiés ou non, émanant des établissements d'enseignement et de recherche français ou étrangers, des laboratoires publics ou privés. 
Research Paper for Biophysical Chemistry

\section{Evaluation of photosynthetic electrons derivation by exogenous redox mediators}

Guillaume Longatte, ${ }^{\mathrm{a}}$ Han-Yi Fu, ${ }^{\mathrm{b}}$ Olivier Buriez, ${ }^{\mathrm{a}}$ Eric Labbé, ${ }^{\mathrm{a}}$ Francis-André Wollman, ${ }^{\mathrm{b}}$ Christian Amatore, ${ }^{\mathrm{a}}$ Fabrice Rappaport, ${ }^{\mathrm{b}}$ Manon Guille-Collignon, ${ }^{\mathrm{a}}$ Frédéric Lemaître ${ }^{\mathrm{a}}$

a) Ecole Normale Supérieure-PSL Research University, Département de Chimie, Sorbonne Universités - UPMC Univ Paris 06, CNRS UMR 8640 PASTEUR, 24, rue Lhomond, 75005 Paris, France.

b) Laboratoire de physiologie membranaire et moléculaire du chloroplaste, CNRS, UPMC UMR 7141, I.B.PC., 13 rue Pierre et Marie Curie, 75005 Paris, France

Number of tables: 2

Number of figures: 8

Number of schemes: 1 


\begin{abstract}
Oxygenic photosynthesis is the complex process that occurs in plants or algae by which the energy from the sun is converted into an electrochemical potential that drives the assimilation of carbon dioxide and the synthesis of carbohydrates. Quinones belong to a family of species commonly found in key processes of the Living, like photosynthesis or respiration, in which they act as electrons transporters. This makes this class of molecules a popular candidate for biofuel cell and bioenergy applications insofar as they can be used as cargo to ship electrons to an electrode immersed in the cellular suspension. Nevertheless, such electron carriers are mostly selected empirically. This is why we report on a method involving fluorescence measurements to estimate the ability of seven different quinones to accept photosynthetic electrons downstream of photosystem II, the first protein complex in the light-dependent reactions of oxygenic photosynthesis. To this aim we use a mutant of Chlamydomonas reinhardtii, a unicellular green alga, impaired in electron downstream of photosystem II and assess the ability of quinones to restore electron flow by fluorescence. In this work, we defined and extracted a "derivation parameter" D that indicates the derivation efficiency of the exogenous quinones investigated. D then allows electing 2,6-dichlorobenzoquinone, 2,5dichlorobenzoquinone and p-phenylbenzoquinone as good candidates. More particularly, our investigations suggested that other key parameters like the partition of quinones between different cellular compartments and their propensity to saturate these various compartments should also be taken into account in the process of selecting exogenous quinones for the purpose of deriving photoelectrons from intact algae.
\end{abstract}

Keywords: photosynthesis, quinones, fluorescence, electronic derivation yield, Chlamydomonas reinhardtii algae, photosystem II, chloroplasts, membranes 


\section{Introduction}

Quinones constitute a family of ubiquitous molecules playing a key role in fundamental biological processes. In particular, they act as electrons carriers in key mechanisms of Life such as anaerobic or aerobic respiration (menaquinone or ubiquinone) or photosynthesis (plastoquinone).[1] Indeed, in both cases, the oxidised form Q can act as an electron acceptor readily converted into its doubly-reduced and protonated-form $\mathrm{QH}_{2}$, which, being neutral and soluble in the membrane can shuttle electrons along the respiratory and photosynthetic chains. This is probably one of the main reasons why quinones are preferably used as exogenous redox mediators in biofuels cells to partially short-circuit the electron transfer involved during photosynthesis[2] (in cyanobacteria,[3, 4] protoplasts,[5] isolated thylakoid membranes[6, 7] or isolated photosystem II complexes[8, 9]) or microbial metabolism[10, 11] and to subsequently shuttle electrons from the biological chain to the man-made electrode surface.

This applies in particular to the extraction of photosynthetic electrons since some quinones appear among electron acceptors of the photosystem II. Along these lines, recent works took benefits of such properties to derive electrons from photosynthesis and thereby obtained promising oxidation current densities.[6,8] Yet, there are many different types of quinones whose structure and physico-chemical properties differ. Until now, the quinones used in experiments aimed at coupling the photosynthetic electron transfer chain to an electrode have been selected empirically. Yet, beyond basic requirements such as appropriate standard potentials of the $\mathrm{QH}_{2} / \mathrm{Q}$ couple with respect to the different steps involved during the electron transfer, several other parameters such as solubility, partition between the different phases, reactivity at the electrode surface, to mention a few, are expected to matter as well in determining the overall efficiency of the derivation methodology.

In this work we thus describe a systematic approach based on fluorescence measurements through which we have analysed the ability of several quinones to extract photosynthetic electrons from chloroplasts and particularly from photosystem II. To do so, an intact biological system (algae containing chloroplasts instead of isolated thylakoid membranes, see Scheme 1) was considered in order to preserve as much as possible the integrity and the physiology of the system.

In this work, a related "derivation parameter" D was determined for estimating the derivation efficiency of the exogenous quinones investigated. Additionally, this work established that other aspects than the redox properties of quinones have to be taken into 
account, notably the partition of quinones between membranes and other aqueous compartments that could alter the quinone concentration available for the derivation.

\section{Experimental Section}

\section{Cell culture and preparation}

Chlamydomonas Reinhardtii $\Delta$ petA mutant[12] that corresponds to cells lacking cytochrome $b_{6} f$ was used in this work. The cytochrome $b_{6} \mathrm{f}$ complex is a quinol:plastocyanin oxidoreductase in the absence of which the plastoquinol generated by the light-induced turnovers of Photosystem II cannot be reoxidized leading to the rapid arrest of light driven electron flow. The respective ability of several distinct quinones to rescue the electron flow was characterized, using fluorescence to assess the Photosystem II photochemical rate.[13] Briefly, cells were grown in Tris Acetate Phosphate medium (TAP) containing Tris base (20 mmol.L $\left.{ }^{-1}\right), \mathrm{NH}_{4} \mathrm{Cl}\left(7 \mathrm{mmol} . \mathrm{L}^{-1}\right), \mathrm{MgSO}_{4}\left(0.83 \mathrm{mmol} \cdot \mathrm{L}^{-1}\right), \mathrm{CaCl}_{2}\left(0.45 \mathrm{mmol} . \mathrm{L}^{-1}\right), \mathrm{K}_{2} \mathrm{HPO}_{4}$ $\left(1.65 \mathrm{mmol} . \mathrm{L}^{-1}\right), \mathrm{KH}_{2} \mathrm{PO}_{4}\left(1.05 \mathrm{mmol} . \mathrm{L}^{-1}\right)$ at $25^{\circ} \mathrm{C}$ under rather dimlight conditions $\left(50 \mu \mathrm{E} . \mathrm{m}^{-}\right.$ $\left.{ }^{2} \cdot \mathrm{s}^{-1}\right)$ to a concentration of $10^{7}$ cells. $\mathrm{mL}^{-1}$.

\section{Chemical materials and solutions preparation}

All chemicals have been purchased from sigma Aldrich and have been used without any further purification. Quinones were dissolved in absolute ethanol in order to make mother concentrated solutions (typically $10 \mathrm{mmol} . \mathrm{L}^{-1}$ ). Appropriate small volumes of such quinone solutions were thus directly added into a cuvette containing the algae suspension in TAP $(\mathrm{V}=$ $2 \mathrm{~mL}$ ) to reach the final expected concentration. The cuvette was then stirred manually before experiments.

\section{Fluorescence Measurements and Data acquisition}

Fluorescence intensities were measured by using a JTS spectrophotometer (Biologic) in which fluorescence was sampled with short flashes ( $4 \mu$ s duration) with negligible actinic effect. The detecting light was provided by white LED's and the wavelength defined by a combination of $3 \mathrm{~mm} \mathrm{BG39}$ and BG3 Schott filters. The actinic light was provided by a red LED $(640 \mathrm{~nm})$. Fluorescence value $\mathrm{F}_{\max }$ was measured $100 \mu \mathrm{s}$ after a saturating pulse of 250 ms duration to induce a full reduction of the electrons acceptors. 


\section{Electrochemical measurements}

Cyclic voltammetry experiments were performed in PBS at pH 7.4 in a standard threeelectrode cell with an Autolab potentiostat (PGSTAT 20). The concentration of the quinones investigated was $0.5 \mathrm{mM}$. The reference electrode was a saturated calomel electrode (SCE). The auxiliary electrode was a platinum wire. For all voltammetric measurements, the working electrode was a vitreous carbon electrode ( $3 \mathrm{~mm}$ in diameter). The half-potential value $\mathrm{E}_{1 / 2}$ is defined as the average of the two (anodic and cathodic) peak potentials.

\section{Simulations and Data treatment}

Simulations and data treatment were performed by using OriginPro 8.1 software (OriginLab company, Northampton, MA 01060 USA).

\section{Results and Discussion}

Experiments were performed with a suspension of photosynthetic cells (unicellular green alga Chlamydomonas reinardtii in TAP medium; $\mathrm{C}=10^{7}$ cells. $\mathrm{mL}^{-1}$ ) with different concentrations of quinones retained as appropriate photosystem II acceptors owing to their redox properties (Figure 1).[14] To characterize the efficiency of quinones to derive photosynthetic electrons just downstream the photosystem II, a mutant of Chlamydomonas reinhardtii, $\Delta$ petA, which lacks the $\mathrm{b}_{6} \mathrm{f}$ complex was used.[12] In this mutant, no light induced electron transfer can take place unless when rescued by added quinones (Scheme 1). This provides a reliable way to specifically assess the electron accepting capacities of exogenous quinones with as little as possible interference from the endogenous electron transfer chain downstream the photosystem II.

\section{Definition of an electronic derivation parameter $D$ for exogenous quinones}

Light absorption by Photosystem II promotes the formation of a chlorophyll excited state (so-called $\mathrm{Chl}_{\mathrm{D} 1}$ ) which can then decay following three different routes: i) charge separation via electron transfer to the neighboring $\mathrm{Pheo}_{\mathrm{D} 1}$, ii) radiative decay or iii) non radiative decay (see ref [14] for a review) (Figure 2).Thus, fluorescence competes with electron transfer and thereby provides a powerful tool to assess the respective yields of the competing pathways 
(see [13]). In practice, one usually distinguishes three fluorescence parameters: $F_{0}$, the fluorescence signal of the dark adapted sample, i.e. under conditions where the Photosystem II photochemical conversion capacity is maximum, $\mathrm{F}_{\max }$, the fluorescence signal of the light saturated sample, i.e. under conditions where the photochemical conversion capacity of Photosystem II is zero, and $\mathrm{F}_{\text {stat, }}$, the steady state level of fluorescence under continuous illumination. Genty et al.,[15] following the steps of Joliot et al. showed that the fraction of absorbed light that is effectively converted into electrochemical potential is proportional to $\left(F_{\max }-F_{\text {stat }}\right) \cdot[16]$ This provides a relatively straightforward way to measure the photochemical yield of Photosystem II and its dependence upon quinone addition. Figure 3A illustrates a typical experimental protocol ( $\mathrm{F}$ represents the fluorescence levels recorded in absence of exogenous quinones and F' corresponds to experiments with exogenous quinones) and compares the fluorescence changes observed upon illumination of cells in the absence and presence of $30 \mu \mathrm{M} 2,6-\mathrm{DCBQ}$. It is observed that addition of the latter compound results in a marked decrease of the $F_{\text {stat }}$ level (Figure 3A). However, quinones can also act as fluorescence quenchers, $[17,18]$ so that assigning the decreased $F_{\text {stat }}$ only to an electron flux from PSII to the exogenous is premature at this stage. In order to assess the quenching induced by quinone addition, a short $(250 \mathrm{~ms})$ saturating pulse of exciting light is superimposed to the continuous illumination. Since the light intensity is then such that the rate at which light quanta are absorbed by PSII largely exceeds the following steps of the downstream electron transfer chain, this saturating light pulse promotes the full reduction of the quinone primary electro-acceptor $\mathrm{Q}_{\mathrm{A}}$ thereby shifting all PSII reaction centers to their closed state. Would the tested quinone acts as a quencher it would modify the fluorescence yield, $F_{\max }$, measured under these conditions. This is illustrated in Figure 3B which evidences that the $\mathrm{F}^{\prime}{ }_{\text {max }}$ value reached in the presence of $30 \mu \mathrm{M}$ of quinones was much lower than that, $F_{\max }$, reached in their absence. This provides a direct way for evaluating the quenching induced by quinone addition and may be separated from electron derivation. Indeed, the F' max $^{\prime}$ level is well above the $\mathrm{F}_{\text {stat }}$ one due to the net flow of electrons taking place when quinones are added. One thus can define a first quantitative parameter $D_{1}$ that corresponds to the fluorescence variation reflecting the electrons derivation yield induced by exogenous quinones $\left(F^{\prime}{ }_{\max }-F^{\prime}{ }_{\text {stat }}\right)$ normalized by the maximum fluorescence change $\left(F^{\prime}{ }_{\text {max }}-F^{\prime}{ }_{0}\right)$ which serves as an internal standard:

$$
D_{1}=\frac{F_{\text {max }}^{\prime}-F_{\text {stat }}^{\prime}}{F_{\text {max }}^{\prime}-F_{0}^{\prime}}
$$


However, particularly at low excitation intensities, applying a saturating pulse in the absence of quinone induces a fluorescence increase from $F_{\text {stat }}$ to a $F_{\max }$ value thus showing the occurrence of a residual endogenous electron flux despite the absence of $b_{6} f$ complex (Figure 3B). This flux has been assigned to the quinol oxidizing activity of PTOX, in addition to a back reaction effect which, though being sluggish,[19, 20] is mostly observed under low photochemical turnover rates. In any case, this endogenous flux must be taken into account when determining the electron outflux to exogenous quinones (see for instance a strong derivation in Figure 3A-B for 2,6-DCBQ and a low derivation for naphtoquinone in Figure 4). One may then define the endogenous electron flux $D_{2}$ as the difference $\left(F_{\max }-F_{\text {stat }}\right)$ normalized by the whole fluorescence variation $\left(\mathrm{F}_{\max }-\mathrm{F}_{0}\right)$ :

$$
D_{2}=\frac{F_{\text {max }}-F_{\text {stat }}}{F_{\text {max }}-F_{0}}
$$

This allows defining the following normalized parameter $\mathrm{D}$ which specifically characterizes the proportion (or ratio) of photosynthetic electrons derived by any given exogenous quinone :

$$
D=D_{1}-D_{2}=\frac{F_{\text {max }}^{\prime}-F_{\text {stat }}^{\prime}}{F_{\text {max }}^{\prime}-F_{0}^{\prime}}-\frac{F_{\text {max }}-F_{\text {stat }}}{F_{\text {max }}-F_{0}}
$$

D ranges from 0 (no electrons derivation) to 1 (maximum electrons derivation).

Furthermore, the same parameter can be deduced through thinking in terms of open reaction center, ready to perform productive photochemistry, and closed reaction centers, with transiently non-functional photochemistry.[21] In other words, an open Photosystem II reaction center has its primary quinone electron acceptor $\mathrm{Q}_{\mathrm{A}}$ in its oxidized state and can thus undergo a stable charge separation whereas when $\mathrm{Q}_{\mathrm{A}}$ is reduced, charge separation will be followed by fast charge recombination and enhance the fluorescence yield owing to the larger probability to decay via the Chl excited state (see [22] and [23] for a recent review). In that way, the fluorescence value in presence of quinones can be expressed as $\mathrm{F}^{\prime}=\mathrm{p}_{\mathrm{O}} \mathrm{F}^{\prime}{ }_{0}+(1-$ $\left.\mathrm{p}_{\mathrm{O}}\right) \mathrm{F}^{\prime}{ }_{\text {max }}$, with $\mathrm{p}_{\mathrm{O}}$ being the percentage of open centers. Thus, $\mathrm{p}_{\mathrm{O}}$ is equal to $\left(\mathrm{F}_{\max }^{\prime}-\mathrm{F}^{\prime}\right) /\left(\mathrm{F}_{\max }^{\prime}\right.$ - $\mathrm{F}_{0}{ }_{0}$ ). Considering the electron derivation yield $\mathrm{D}$ induced by the exogenous quinones as the ratio of open centers due to the quinones presence, $\mathrm{D}$ corresponds to the difference between 
the number of open centers with and without quinones. Considering the same levels of fluorescence in absence of quinones $\left(\mathrm{F}_{\text {stat }}, \mathrm{F}_{\max }, \mathrm{F}_{\text {stat }}, \mathrm{F}_{0}\right)$ gives rise exactly to the same equation as (3).

The efficiency of the various quinones described in Figure $\mathbf{1}$ could then be characterized by their parameter D values defined as a function of their extracellular concentration (Figure 5). This graph shows that, as expected, the ability to accept electrons from PSII saturates at high concentration. Interestingly, all $\mathrm{D}=\mathrm{f}(\mathrm{C})$ curves exhibit a sigmoidal and thus a clear deviation from the shape of a simple saturation curve expected at low concentrations. This cannot be accounted by the redox properties but evidences that the quinones availability near the center of interest is limited by a competitive process. A reasonable assumption consists in envisioning that cellular compartments other than the thylakoid membrane where electron transfer takes place, may sequester the quinones thereby preventing them from accessing the thylakoid. Indeed, quinones need crossing several membranes (from TAP medium external solution to the cytoplasm, from the cytoplasm to the stroma and finally from the stroma to the thylakoid membrane) to reach the targeted photosystem II (Scheme 1), so that a fraction of their bulk amount is certainly partitioned among these different membranes. A very likely candidate is the mitochondrial network in which the exogenous quinones may also interact with the respiratory electron transfer chain. Actually, we did note that long incubation time (several hours, i.e. much longer than the duration of the experiments described here) hampered respiration as witnessed by the progressive reduction of the plastoquinone pool.

Correction of the exogenous quinones concentration in solution by a partition effect into membrane

This sequestering hypothesis can be tested using another observable which is also expected to depend on the specific concentration of quinones in the thylakoid membrane: $\mathrm{F}^{\prime}{ }_{\text {max. }}$ Indeed, it is well known that quinone can interact with excited chlorophyll $\left(\mathrm{Chl}^{*}\right)$ in solution and form transient charge transfer states (see [24] and [25] for a review). At variance with $\mathrm{Chl}^{*}$ the decay of such a charge transfer state to the ground state cannot be associated with the emission of a photon. Thus quinones are efficient fluorescence quenchers.[17, 18] In addition, and of importance for our purpose, such a quenching is nicely described by the Stern-Volmer's law:[17, 18] 


$$
F_{\text {max }}^{\prime}=\frac{F_{\text {max }}}{1+K C}
$$

where $\mathrm{K}$ is the Stern-Volmer's constant and $\mathrm{C}$ the concentration of the quencher.

Since there is no free chlorophyll in solution here, the quenching necessarily occurs within thylakoid membranes. However, free quinones in solution also have to be taken into account since they can easily diffuse from the solution to the targeted thylakoid membrane. Therefore, the Stern-Volmer's law can apply to the total quinone concentration but using a SternVolmer's constant $\mathrm{K}$ ' lower than the real constant $\mathrm{K}$, to take into account the partitioning of the quinones. Thus the $\frac{F_{\max }-F_{\text {max }}^{\prime}}{F_{\text {max }}^{\prime}}$ ratio provides an indirect measurement of the concentration of quinones available for quenching.

As shown in Figure 6 (for quinone PPBQ), the plot of $\frac{F_{\max }-F^{\prime}{ }_{\max }}{F^{\prime}{ }_{\max }}$ as a function of the concentration of added quinones shows two concentration ranges each one being characterized by a specific slope. Let us consider, as suggested above, that quinones should partition between different media. A first population will be located in compartments in which quinones are available for quenching pathways (thylakoid membrane in equilibrium with the solution). The other population is located in those other intracellular compartments which can sequester quinones away from the chlorophyll containing membranes, thus preventing their involvement in quenching processes. Using this simple model, the respective concentrations of the two quinone populations can be denoted as $C_{Q}$ and $C_{R} \cdot C_{Q}$ and $C_{R}$ are related to the amount of quinones available and not available for quenching processes respectively. Notably, these quantities are defined therein with respect to the total volume and not to that of the specific compartment under consideration.

One may then define a pseudo-partition constant k' that applies at low quinone concentrations, i.e. when saturation effects cannot occur:

$$
k^{\prime}=\frac{C_{R}}{C_{Q}}
$$

Using the conservation of matter, one has :

$$
C_{\text {tot }}=C_{Q}+C_{R}
$$


Combining (5) and (6) gives :

$$
C_{Q}=\frac{C_{t o t}}{1+k^{\prime}}
$$

Thus,

$$
\frac{F_{\text {max }}-F_{\text {max }}^{\prime}}{F_{\text {max }}^{\prime}}=K^{\prime} C_{Q}=K^{\prime} \frac{C_{\text {tot }}}{1+k^{\prime}}
$$

When saturation of all these sequestering compartments is achieved, viz., at higher quinone concentrations, equation (5) no longer applies and $C_{R}$ is equal to its maximum value (defined as " $\mathrm{C}_{\text {sat }}$ "). One has thus :

$$
C_{Q}=C_{t o t}-C_{s a t}
$$

which finally provides after combining with Stern-Volmer's law :

$$
\frac{F_{\text {max }}-F_{\text {max }}^{\prime}}{F_{\text {max }}^{\prime}}=K^{\prime}\left(C_{t o t}-C_{s a t}\right)=-K^{\prime} C_{s a t}+K^{\prime} C_{t o t}
$$

Two different quenching behaviors are thus predicted depending on the bulk concentration of added quinone. At low concentration values, quenching would hardly increase with $\mathrm{C}_{\text {tot }}$ and above it would follow a linear relationship with a slope $\left(\mathrm{K}^{\prime}\right)$ and an intercept with the $y$ axis equal to $-\mathrm{K}^{\prime} \mathrm{C}_{\mathrm{sat}}$, which affords $\mathrm{C}_{\mathrm{sat}}$ value. Such a description nicely accounts for the observed dependence of quenching upon the concentration of added quinone (see Figure 6). Interestingly, the deviation from strict linearity described here had not been observed when using broken chloroplast.[17] This provides indirect support to the above framework since the compartmentalization described here appears to be specific to intact cells. Beyond the determination of the $\mathrm{K}^{\prime}$ and $\mathrm{C}_{\text {sat }}$, $\mathrm{k}$ ' values can also be deduced by considering the range of low quinone concentrations. This finally allows calculating the available quinones concentration $\mathrm{C}_{\mathrm{Q}}$ for the two behaviors delineated here (see equations (11) and (12)) and eventually provides suitable corrections to determine the electron derivation parameter as a function of the effective quinone concentration (see below). 


$$
\begin{aligned}
& C_{Q}=\frac{C_{t o t}}{1+k^{\prime}} \\
& C_{Q}=C_{t o t}-C_{s a t}
\end{aligned}
$$

Quantification of the electron derivation yield by the exogenous quinones: simulations of the electronic parameter $D$ to select the high derivating efficiency of quinones

In order to extract quantitative values from our data, the various $D=f$ (corrected concentrations) can be correctly fitted by considering that the derivation yield corresponds to Michaelis-Menten kinetics (Figure 7). To do so, the derivation value $\mathrm{D}_{\infty}$ reached at infinite quinone concentration and the initial slope $S_{0}$ were determined (Table 1). While $C_{\text {sat }}$ allows characterizing accurately the relevant concentration of quinones effectively involved in quenching, their ability to derive electron requires at least two parameters, $D_{\infty}$ and $S_{0}$, which, together, provide a useful picture in this respect knowing that a high derivating quinone has high $\mathrm{D}_{\infty}$ and $\mathrm{S}_{0}$ values. Accordingly, 2,6-DCBQ, 2,5-DCBQ and PPBQ are the most efficient quinones whereas BQ, NBQ, 2,6-DMBQ and 2,5-DMBQ are the less potent. Furthermore, in certain cases, the saturation limit could not be experimentally observed in the range of concentrations investigated here, thus resulting to a non-reliable value of $D_{\infty}$ which is therefore not mentioned in Table 1. It is worth mentioning that the ability for a given quinone to derivate the photosynthetic electrons can be correlated to the half potential values determined by cyclic voltammetry only for some quinones. As an instance, the lowest deriving quinones (NBQ and $\mathrm{BQ}$ ) correspond to very negative half-potentials while the highest deriving quinones (2,6- and 2,5-DCBQ) are related to the larger half-potentials values. However, the correlation is more difficult to establish for the other quinones, thus suggesting that other points (interactions with and penetration into the targeted site downstream the photosystem II, crossing membrane kinetics...) should be taken into account to rationalize the derivation properties of quinones.

After having selected several quinones as good candidates to extract electrons from Photosystem II, we further characterized them in this respect by studying their derivation efficiencies as a function of the light intensity (Table 1 and Table 2). For all four selected quinones the apparent Stern-Volmer constant and $\mathrm{C}_{\text {sat }}$ remained unchanged. This brings additional support to the above rationale which implicitly assumes that these two parameters 
are intrinsic properties of the "quinone-sample" system and should not depend on light intensity.

Conversely as expected, the parameters related to the derivation efficiency varied with the light intensity. Globally, the $\mathrm{D}_{\infty}$ and $\mathrm{S}_{0}$ values decreased (see as an example 2,5-DCBQ $\mathrm{D}_{\infty}=$ $0.79 \pm 0.09$ to $0.60 \pm 0.08 ; \mathrm{S}_{0}=(1.4 \pm 0.3) .10^{-1} \mu \mathrm{M}^{-1}$ to $\left.(5.9 \pm 0.5) \cdot 10^{-2} \mu \mathrm{M}^{-1}\right)$ when increasing the light intensity from 135 to $340 \mu \mathrm{E} \cdot \mathrm{m}^{-2} \cdot \mathrm{s}^{-1}$. This decrease of $\mathrm{D}_{\infty}$ simply reflects that the outflux of electron decreases with light intensities, or that, in other terms, the derivation is, in the present conditions, kinetically limited by the photochemical turnover rate of the photoconverters. To further assess this, the effect of light intensity was investigated in more details for 2,5-DCBQ (Figure 8). Figure 8A displays the variations of the derivation parameter D values as a function of the 2,5-DCBQ corrected concentration for different light intensities $\left(I^{\circ}\right)$. Such a graph evidences that the electron derivation yield strongly depends on the light intensity and decreases with increasing light intensity. This stems from the fact that $\mathrm{D}_{\infty}$ is a yield and is thus determined by the competing effect of the light-induced reduction of the primary electron acceptor of PSII $\mathrm{Q}_{\mathrm{A}}$ and its reoxidation by the endo/exogenous quinones. Based on the derivation yield $\mathrm{D}_{\infty}$, one can readily determine the derivation flux $\left(\mathrm{D} \times \mathrm{I}^{\circ}\right)$ by multiplying the yield by the light intensity (in theory, to determine the exact flux one would need to use the photochemical rate of PSII, however, in this intensity range this is proportional to the light intensity [26]. The results for 2,5-DCBQ depicted in Figure 8B show that, as expected, the derivation outflux increases with light intensity whereas, in the intensity range used here, the rate of the process is entirely determined by the frequency of PSII turnovers that can be kinetically controlled by several light independent such as stray electron transfer, diffusion of quinone etc, or by incident light intensity. Thus when the frequency at which PSII's are excited is lower than the rate of the step that kinetically control the oxidation of $\mathrm{Q}_{\mathrm{A}}{ }^{\circ}$, the derivation flux is limited by light intensity, thus resulting into a constant derivation yield as a function of the incident light. This explains why, in the lower light intensity range, the $\left(\mathrm{D} \mathrm{x} \mathrm{I}^{\circ}\right)_{\max }$ value is proportional to the incident light intensity. Conversely, when light intensity becomes high enough to exceed the rate of oxidation of $\mathrm{Q}_{\mathrm{A}}^{\mathrm{O}^{-}}$the derivation flux is determined by the latter, thus leading to a saturation of the $\left(\mathrm{D} \times \mathrm{I}^{\circ}\right)_{\max }$ value as a function of the incident light and to the decrease of the derivation yield with increasing light intensity (see inset in Figure 8B that depicts $\left(\mathrm{D} \times \mathrm{I}^{\circ}\right)_{\max }$ as a function of the light intensity). 


\section{Conclusion}

In this work a variety of quinones (1,4-benzoquinone, 1,4-naphtobenzoquinone, 2,6dichlorobenzoquinone, 2,5-dichlorobenzoquinone, 2,6-dimethylbenzoquinone, 2,5dimethylbenzoquinone, p-phenylbenzoquinone) were benchmarked against their ability to derive electrons from the photosynthetic chain, downstream the photosystem II. Fluorescence was used as a proxy of this derivation and a mutant of Chlamydomonas reinhardtii alga as a model system. The results of the fluorescent measurements led us to define an analytical parameter " $\mathrm{D}$ " viewed as an electronic derivation parameter for exogenous quinones to determine the best candidate to use in derivation experiments on intact algae. Furthermore, the use of Stern-Volmer's law giving the quenching parameter as a function of the introduced exogenous quinone concentration in solution was consistent with a quinone partition into cellular membranes other than the target thylakoid one. However, quinone concentration in solution could be corrected based on a simple partition model that can be viewed as a caveat, namely a possible difference between the introduced quinone concentration and the available one. This allowed analyzing $\mathrm{D}$ as a function of the quinones concentration modified by the partition effect thus giving access to two important analytical parameters characterizing the electronic derivation: the infinite quinone concentration derivation, $\mathrm{D}_{\infty}$, and the initial slope, $\mathrm{S}_{0}$. The most effective derivating quinone are then those with high $\mathrm{D}_{\infty}$ and $\mathrm{S}_{0}$ values as obtained for 2,6-DCBQ, 2,5-DCBQ and PPBQ. Contributions of the selected quinones over short and long time period in electrochemical applications to behave as electron-carriers will be considered in a close future. 


\section{Acknowledgments}

This work has been supported in part by CNRS (UMR 8640, FR2702), Ecole Normale Supérieure, French Ministry of Research, Université Pierre \& Marie Curie Paris 06, the "Fondation Pierre-Gilles de Gennes pour la Recherche" FPGG0049 and the "Initiative d'Excellence" program from the French state (Grant "DYNAMO”, ANR-11-LABX-0011$01)$. 


\section{FIGURES}

Figure 1<smiles>O=C1C=CC(=O)C=C1</smiles>

1,4-Benzoquinone (BQ)<smiles>O=C1C=C(Cl)C(=O)C=C1Cl</smiles><smiles>O=C1C=CC(=O)c2ccccc21</smiles>

1,4-Naphtoquinone (NBQ)<smiles>CC1=CC(=O)C=C(C)C1=O</smiles>

2,6-Dimethylbenzoquinone (2,6-DMBQ)<smiles>O=C1C=CC(=O)C(c2ccccc2)=C1</smiles>
(PPBQ)<smiles>O=C1C=C(Cl)C(=O)C(Cl)=C1</smiles>

2,6-Dichlorobenzoquinone (2,6-DCBQ)<smiles>CC1=CC(=O)C(C)=CC1=O</smiles>

2,5-Dimethylbenzoquinone (2,5-DMBQ) (2,5-DCBQ) 
Figure 2

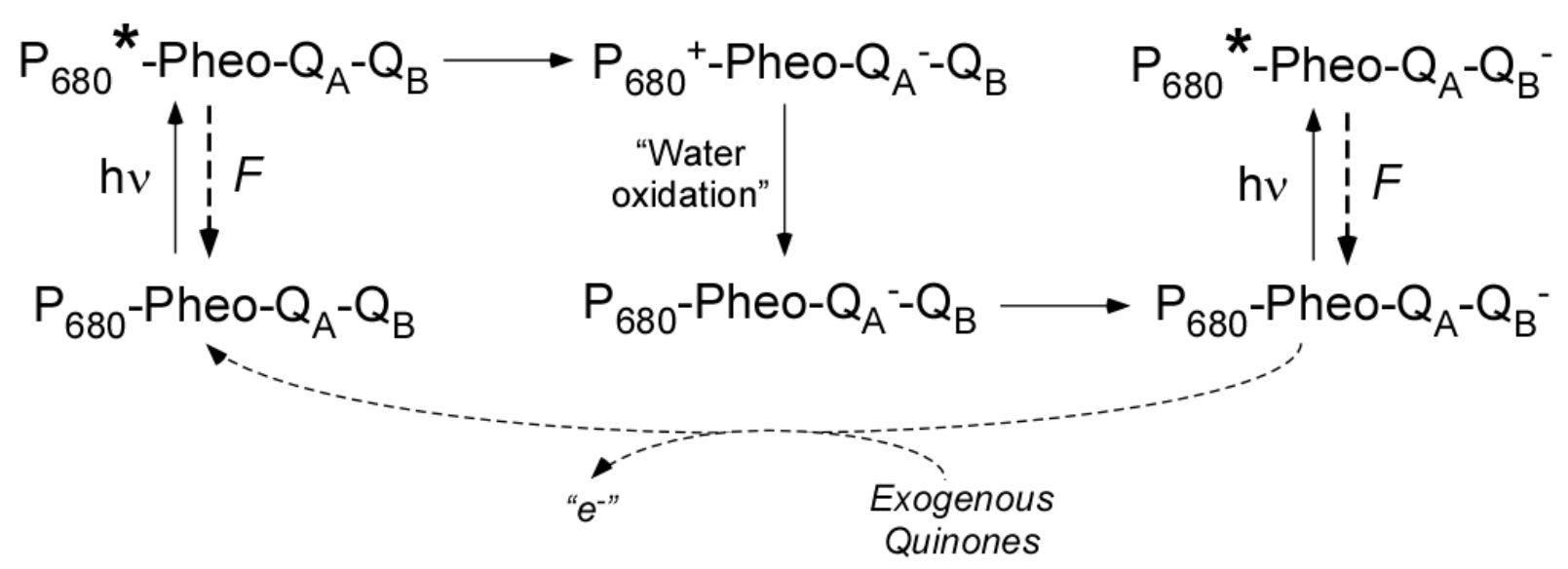

16 
Figure 3

A)

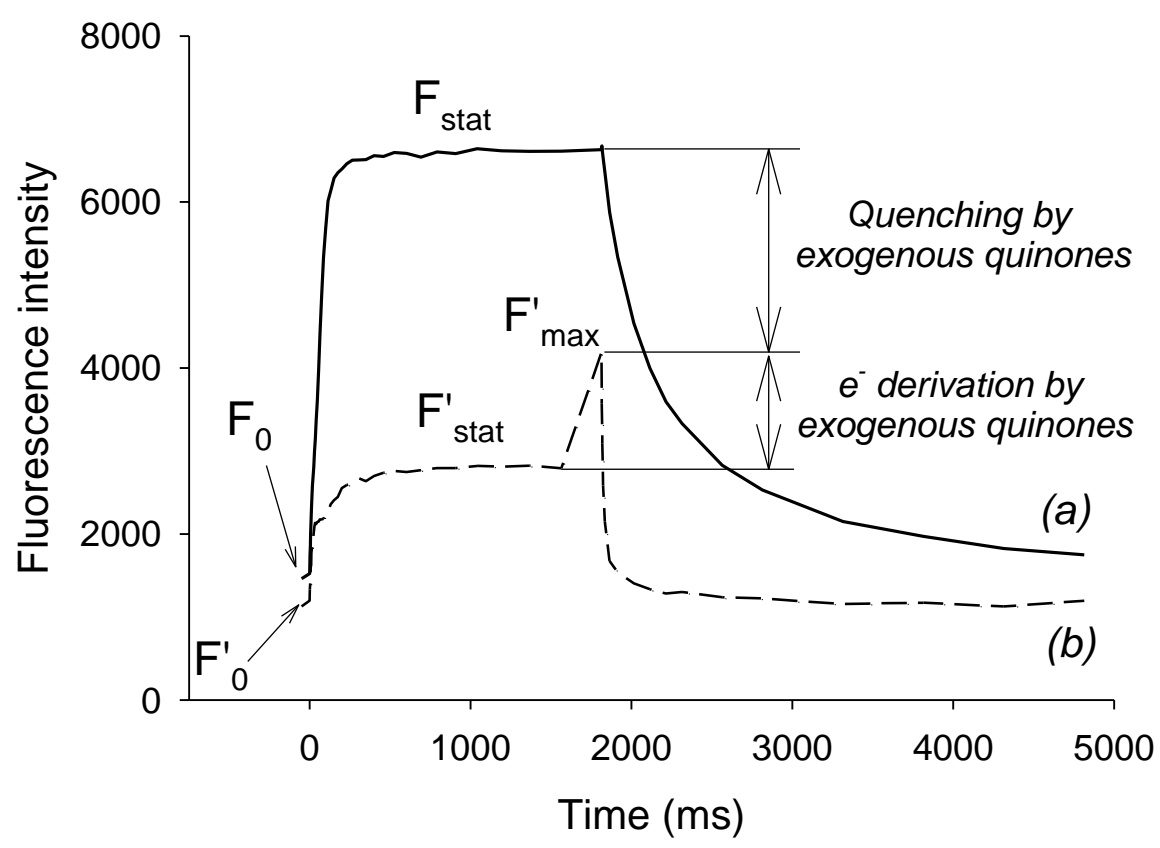

B)

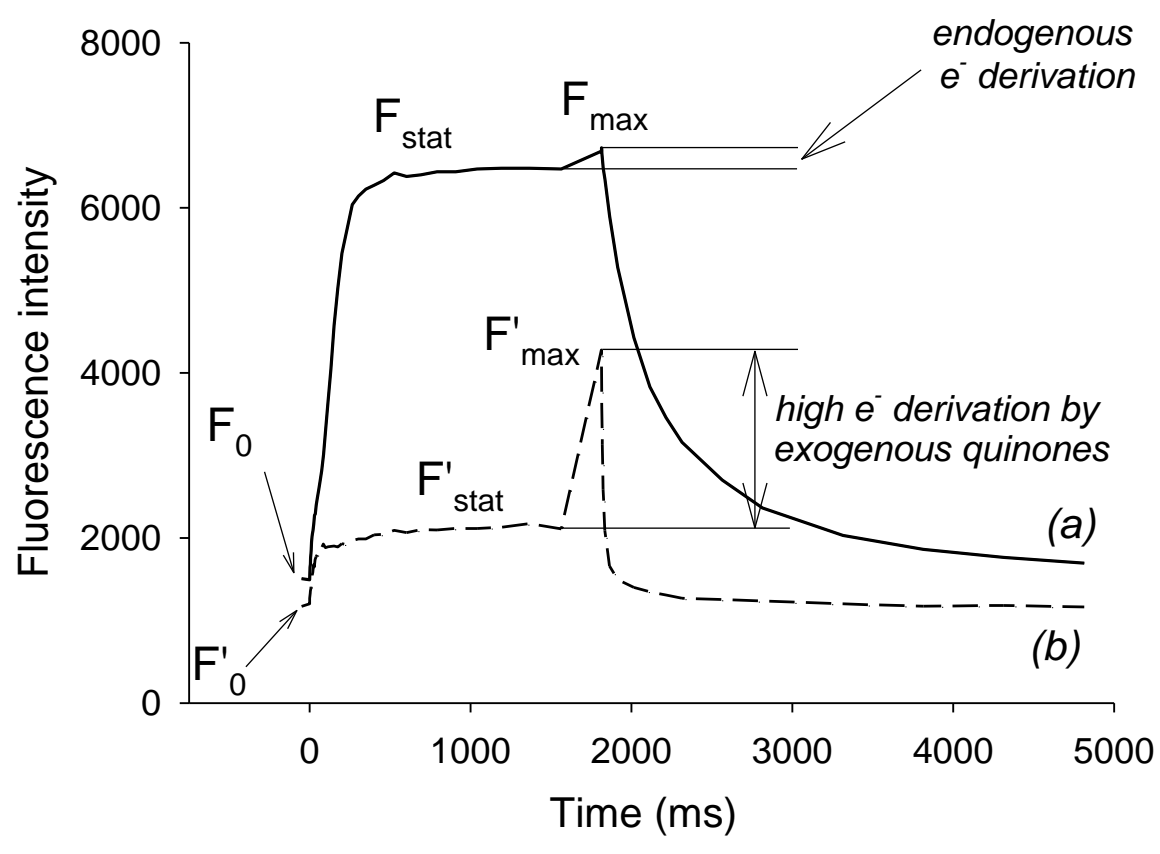


Figure 4

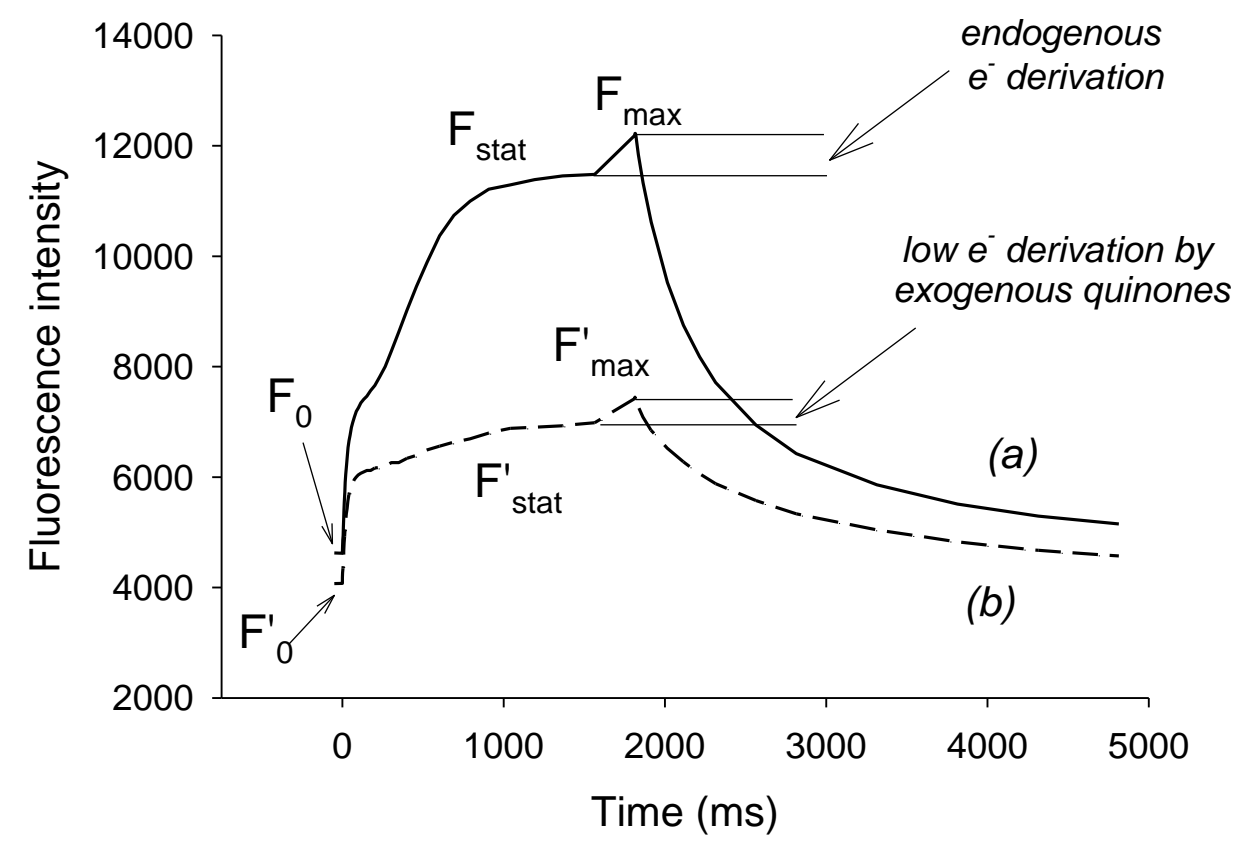


Figure 5

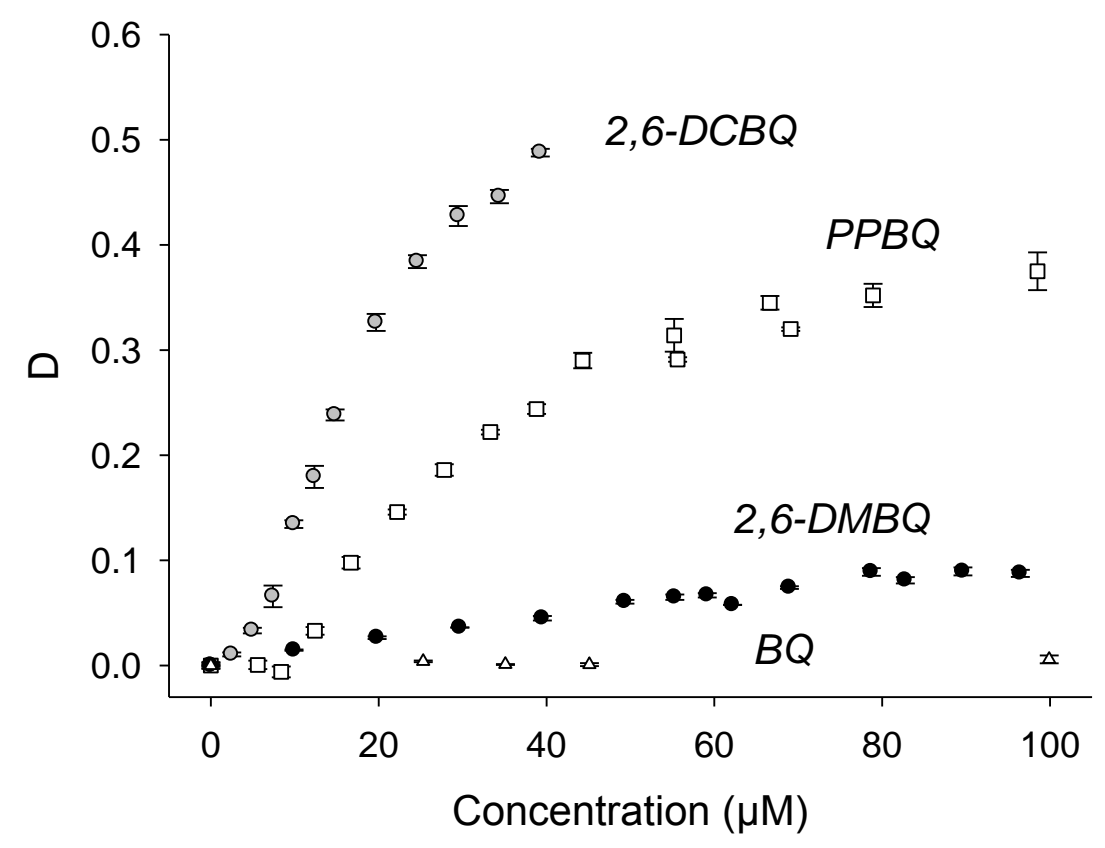


Figure 6

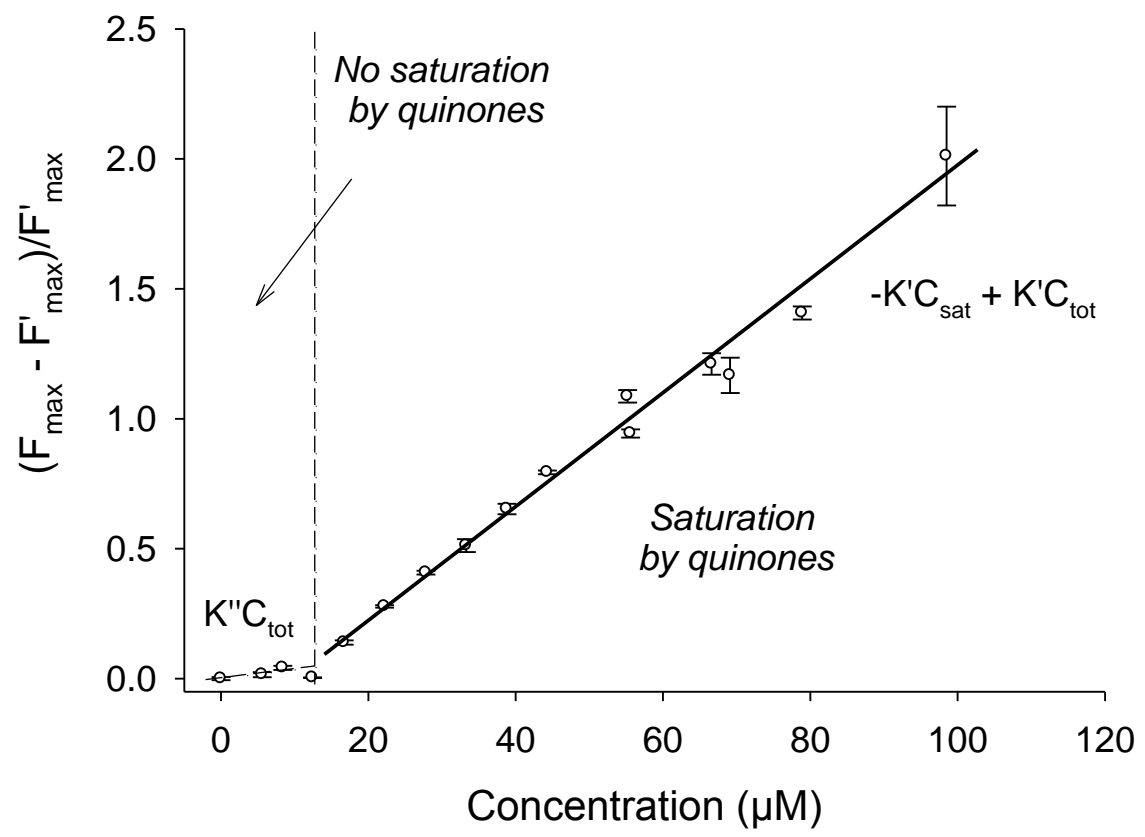


Figure 7

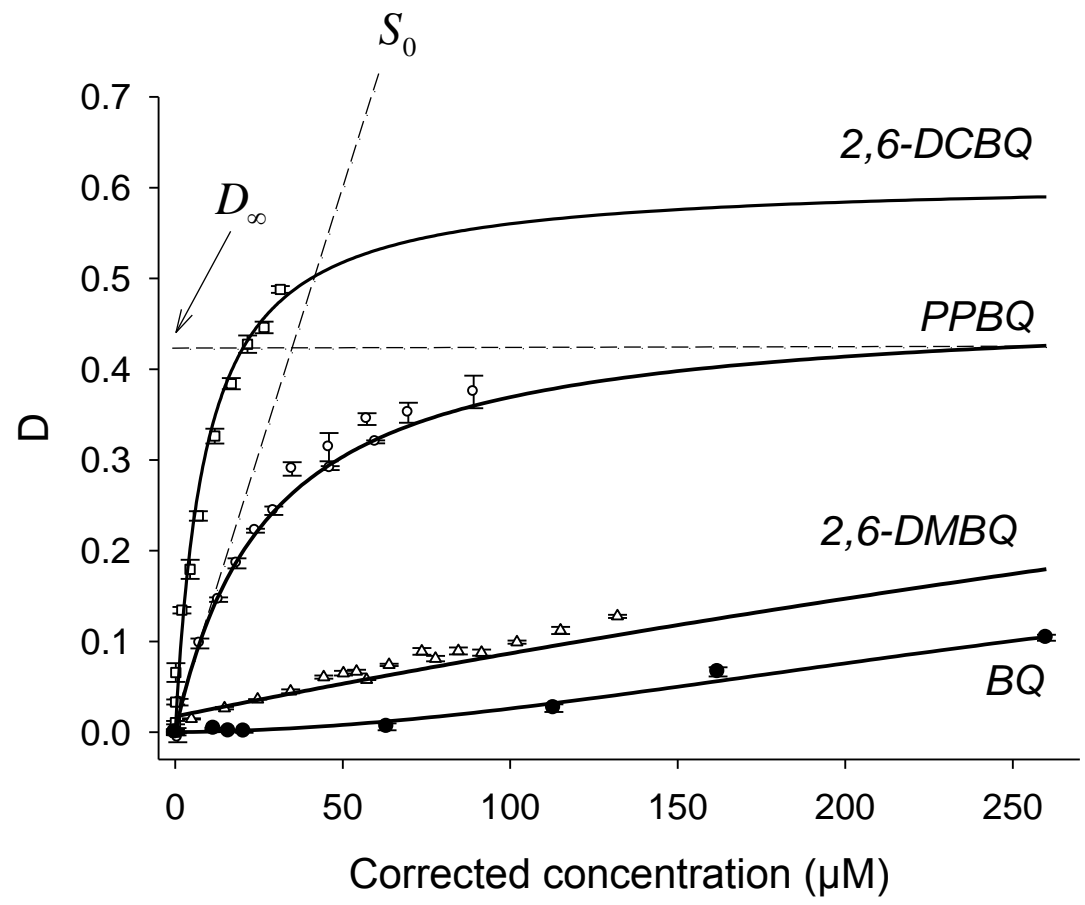




\section{Figure 8}

A)

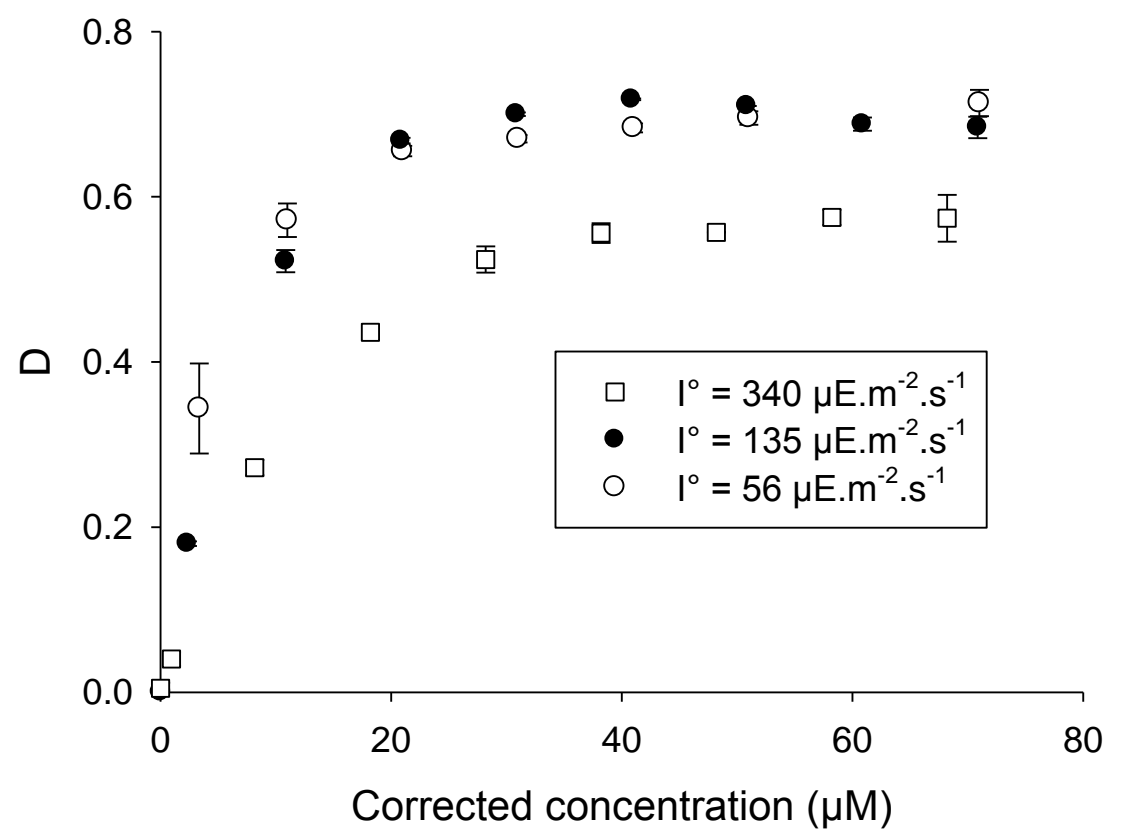

B)

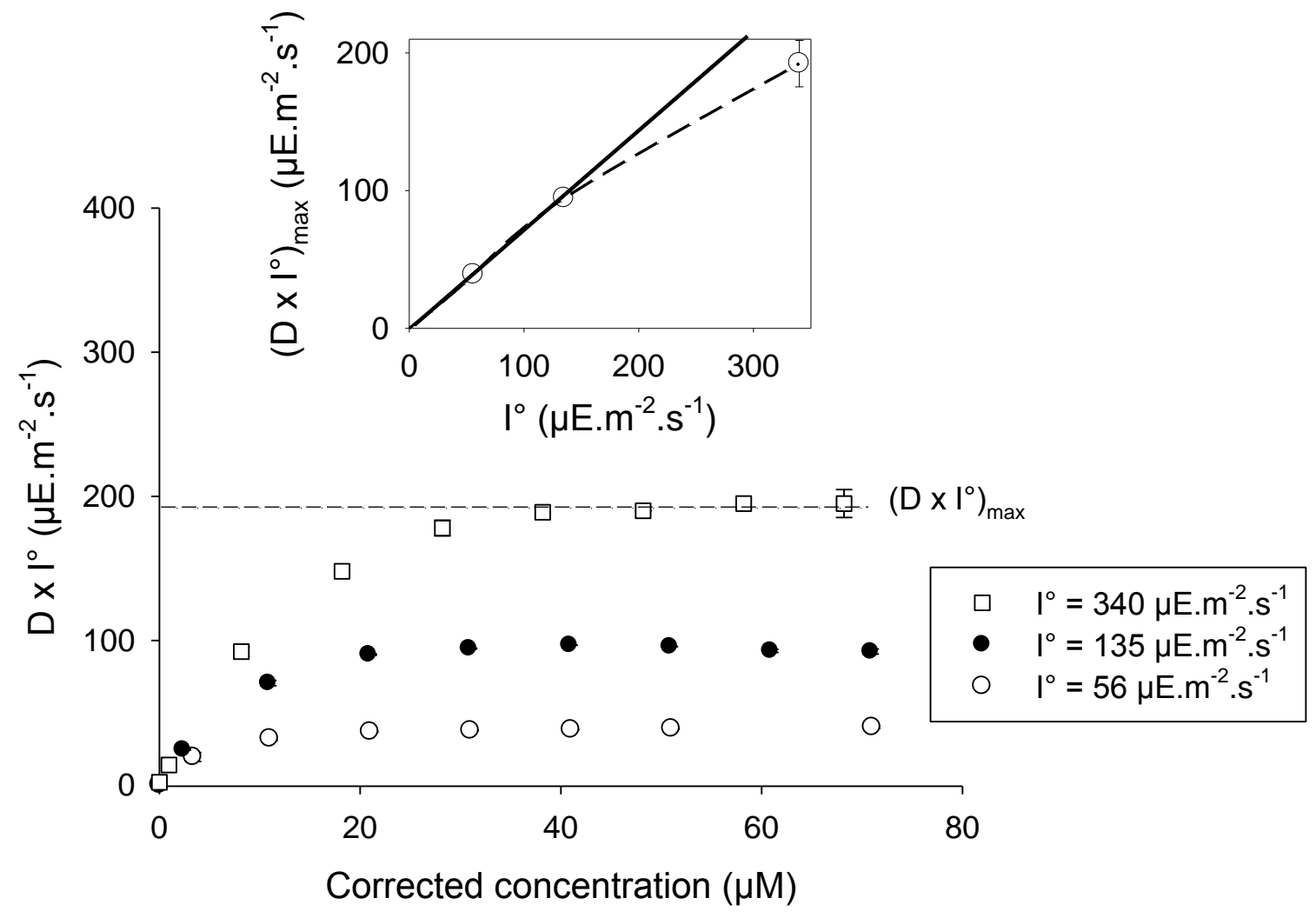


Scheme 1
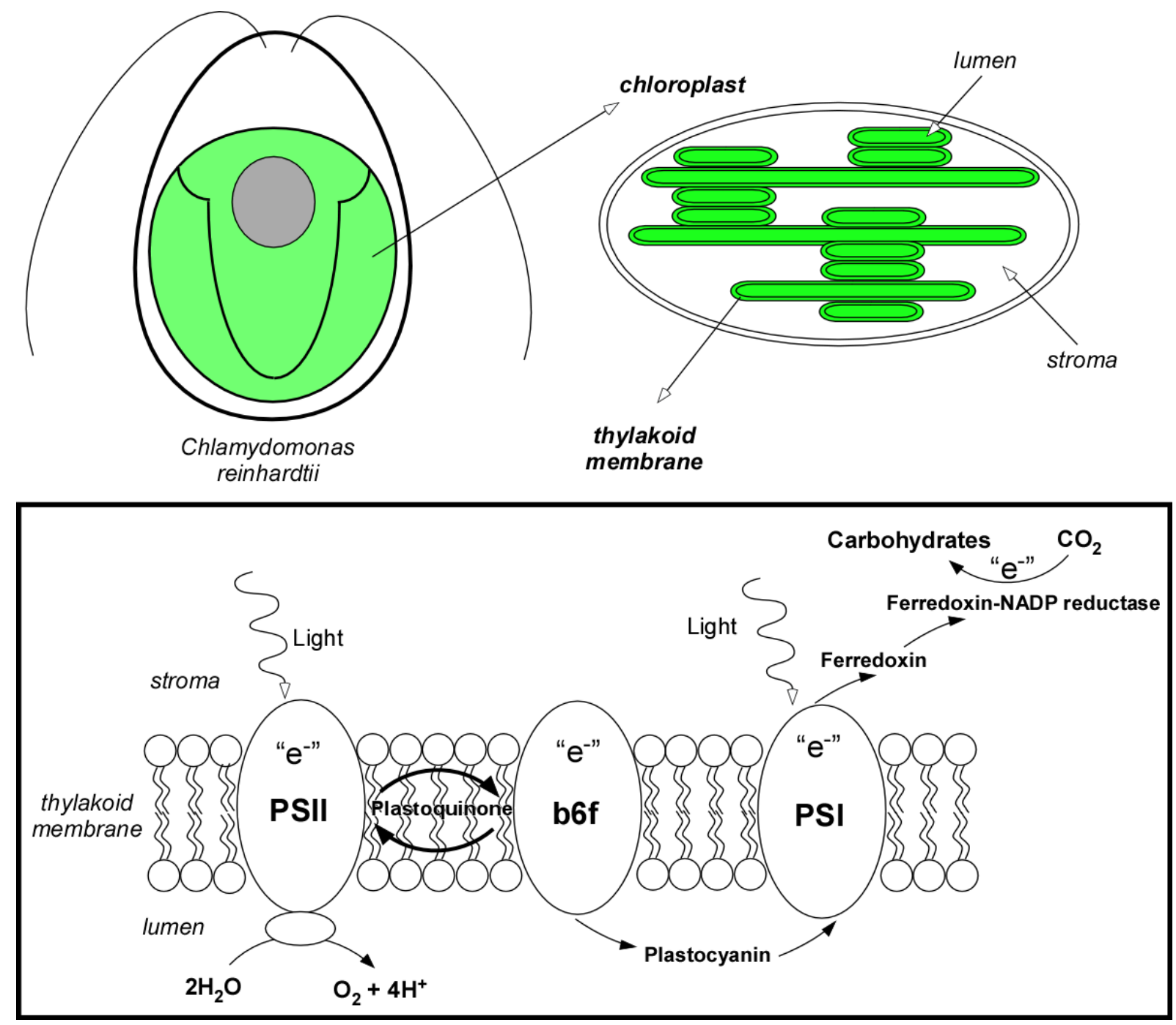
TABLES

\section{Table 1}

Extracted values for different quinones $\left(\mathrm{I}^{\circ}=340 \mu \mathrm{E} \cdot \mathrm{m}^{-2} \cdot \mathrm{s}^{-1}\right)$

\begin{tabular}{|c|c|c|c|c|c|}
\hline & $\mathrm{K}^{\prime}\left(\mathrm{mol}^{-1} . \mathrm{L}\right)$ & $\mathrm{C}_{\mathrm{sat}}\left(\mu \mathrm{mol} . \mathrm{L}^{-1}\right)$ & $\mathrm{D}_{\infty}$ & $\mathrm{S}_{0}\left(\mu \mathrm{mol}^{-1} . \mathrm{L}\right)$ & $\begin{array}{c}\mathrm{E}_{1 / 2}(\mathrm{mV} \text { vs } \\
\mathrm{SCE})\end{array}$ \\
\hline $\begin{array}{c}2,6- \\
\mathrm{DCBQ}\end{array}$ & $(1.84 \pm 0.08) \cdot 10^{4}$ & $19.5 \pm 6.6$ & $0.58 \pm 0.06$ & $(4.1 \pm 1.4) \cdot 10^{-2}$ & +42 \\
\hline $\begin{array}{c}2,5- \\
\text { DCBQ }\end{array}$ & $(2.28 \pm 0.40) \cdot 10^{4}$ & $12.0 \pm 0.2$ & $0.60 \pm 0.08$ & $(5.9 \pm 0.5) \cdot 10^{-2}$ & +55 \\
\hline $\begin{array}{c}2,6- \\
\text { DMBQ }\end{array}$ & $(0.37 \pm 0.04) \cdot 10^{4}$ & $11.9 \pm 6.8$ & $\mathrm{nd}$ & $(9.5 \pm 1.2) \cdot 10^{-4}$ & -60 \\
\hline $\begin{array}{c}2,5- \\
\text { DMBQ }\end{array}$ & $(0.45 \pm 0.06) \cdot 10^{4}$ & $4.1 \pm 0.8$ & $\mathrm{nd}$ & $(7.4 \pm 1.9) \cdot 10^{-4}$ & +8 \\
\hline $\begin{array}{c}\text { PPBQ } \\
\text { BQ }\end{array}$ & $(2.37 \pm 0.19) \cdot 10^{4}$ & $14.3 \pm 4.9$ & $0.48 \pm 0.01$ & $(1.7 \pm 0.1) \cdot 10^{-2}$ & +4 \\
\hline NBQ & $(4.93 \pm 0.52) \cdot 10^{4}$ & $5.0 \pm 1.5$ & $0.10 \pm 0.03$ & $(4.0 \pm 1.4) \cdot 10^{-3}$ & -330 \\
\hline
\end{tabular}

\section{Table 2}

Extracted values for different quinones $\left(\mathrm{I}^{\circ}=135 \mu \mathrm{E} \cdot \mathrm{m}^{-2} \cdot \mathrm{s}^{-1}\right)$

\begin{tabular}{|c|c|c|c|c|}
\hline & $\mathrm{K}^{\prime}\left(\mathrm{mol}^{-1} . \mathrm{L}\right)$ & $\mathrm{C}_{\mathrm{sat}}\left(\mu \mathrm{mol} . \mathrm{L}^{-1}\right)$ & $\mathrm{D}_{\infty}$ & $\mathrm{S}_{0}\left(\mu \mathrm{mol}^{-1} . \mathrm{L}\right)$ \\
\hline $2,6-\mathrm{DCBQ}$ & $(1.77 \pm 0.26) \cdot 10^{4}$ & $14.4 \pm 2.4$ & $0.74 \pm 0.08$ & $(6.9 \pm 1.8) .10^{-2}$ \\
\hline $2,5-\mathrm{DCBQ}$ & $(2.88 \pm 0.46) .10^{4}$ & $11.0 \pm 0.5$ & $0.79 \pm 0.09$ & $(1.4 \pm 0.3) .10^{-1}$ \\
\hline $2,6-\mathrm{DMBQ}$ & $(0.33 \pm 0.04) \cdot 10^{4}$ & $5.4 \pm 3.5$ & $\mathrm{nd}$ & $(1.9 \pm 0.4) .10^{-2}$ \\
\hline $2,5-\mathrm{DMBQ}$ & $(0.53 \pm 0.06) .10^{4}$ & $4.7 \pm 0.9$ & $\mathrm{nd}$ & $(1.8 \pm 0.5) .10^{-2}$ \\
\hline
\end{tabular}




\section{Figure captions}

Figure 1. Chemical structures of the quinones investigated in this study.

Figure 2. Representative scheme of the different pathways taken within the photosystem II after a proper excitation of P680 with or without exogenous quinones.

Figure 3. Typical fluorescence experiments related to the exogenous quinone addition effect as a function of the excitation intensity. A) $\mathrm{I}^{\circ}=340 \mu \mathrm{E} \cdot \mathrm{m}^{-2} \cdot \mathrm{s}^{-1}$ a) without any exogenous quinone (- solid line). b) in presence of 2,6-DCBQ $(30 \mu \mathrm{M}$, --- dashed line $)$. B) $\mathrm{I}^{\circ}=135 \mu \mathrm{E} \cdot \mathrm{m}^{-}$ ${ }^{2} . \mathrm{s}^{-1}$ a) without any exogenous quinone (- solid line). b) in presence of 2,6-DCBQ $(30 \mu \mathrm{M},---$ dashed line).

Figure 4. Example of a low derivation behavior. $\left.\mathrm{I}^{\circ}=135 \mu \mathrm{E} \cdot \mathrm{m}^{-2} \cdot \mathrm{s}^{-1} \mathrm{a}\right)$ without any exogenous quinone (- solid line). b) in presence of NBQ (30 $\mu \mathrm{M},---$ dashed line).

Figure 5. Derivation parameter $D$ (see definition in text) as a function of the quinone concentration in solution $\left(\mathrm{I}^{\circ}=340 \mu \mathrm{E} \cdot \mathrm{m}^{-2} \cdot \mathrm{s}^{-1}\right)$. Only four quinones investigated here are displayed for more clarity.

Figure 6. Quenching parameter (see definition in text) as a function of the quinone concentration in solution $\left(\mathrm{I}^{\circ}=340 \mu \mathrm{E} \cdot \mathrm{m}^{-2} \cdot \mathrm{s}^{-1}\right)$ for PPBQ.

Figure 7. Derivation parameter D (see definition in text) as a function of the corrected quinone concentration as evaluated from its solution value taking into account the partition phenomena. $\mathrm{I}^{\circ}=340 \mu \mathrm{E} \cdot \mathrm{m}^{-2} \cdot \mathrm{s}^{-1}$. Only four quinones among the seven ones investigated are shown but gave rise to a similar Michaelis-Menten behavior through $\mathrm{D}_{\infty}$ cannot be still determined with accuracy (see text).

Figure 8. A) Variations of the derivation parameter D as a function of the 2,5-DCBQ corrected concentration for different light intensities $\left(\mathrm{I}^{\circ}\right)$. B) Electron derivation flux $\left(\mathrm{D} \times \mathrm{I}^{\circ}\right)$ as a function of the 2,5-DCBQ corrected concentration for different light intensities $\left(\mathrm{I}^{\circ}\right)$ (inset : maximum electron derivation flux $\left(\mathrm{D} \mathrm{x} \mathrm{I}^{\circ}\right)_{\max }$ as a function of the light intensity $\left(\mathrm{I}^{\circ}\right)$ ). 


\section{REFERENCES}

[1] B. Schoepp-Cothenet, R. van Lis, A. Atteia, F. Baymann, L. Capowiez, A.-L. Ducluzeau, S. Duval, F. ten Brink, M.J. Russell, W. Nitschke, On the universal core of bioenergetics, Biochim. Biophys. Acta, 1827 (2013) 79-93.

[2] M. Rosenbaum, Z. He, L.T. Angenent, Light energy to bioelectricity: Photosynthetic microbial fuel cells, Curr. Opin. Biotechnol., 21 (2010) 259-264.

[3] M. Torimura, A. Miki, A. Wadano, K. Kano, T. Ikeda, Electrochemical investigation of cyanobacteria synechococcus sp pcc7942-catalyzed photoreduction of exogenous quinones and photoelectrochemical oxidation of water, J. Electroanal. Chem., 496 (2001) 21-28.

[4] M. Kasuno, M. Torimura, Y. Tsukatani, D. Murakami, S. Hanada, T. Matsushita, H. Tao, Characterization of the photoinduced electron transfer reaction from the photosynthetic system in rhodobacter sphaeroides to an exogenous electron acceptor, J. Electroanal. Chem., 636 (2009) 101-106.

[5] T. Yasukawa, I. Uchida, T. Matsue, Microamperometric measurements of photosynthetic activity in a single algal protoplast, Biophys. J., 76 (1999) 1129-1135.

[6] K. Hasan, Y. Dilgin, S.C. Emek, M. Tavahodi, H.-E. Akerlund, P.-A. Albertsson, L. Gorton, Photoelectrochemical communication between thylakoid membranes and gold electrodes through different quinone derivatives, ChemElectroChem, 1 (2014) 131-139.

[7] H. Hamidi, K. Hasan, S.C. Emek, Y. Dilgin, H.-E. Akerlund, P.-A. Albertsson, D. Leech, L. Gorton, Photocurrent generation from thylakoid membranes on osmium-redox-polymermodified electrodes, ChemSuschem, 8 (2015) 990-993.

[8] A. Badura, D. Guschin, B. Esper, T. Kothe, S. Neugebauer, W. Schuhmann, M. Roegner, Photo-induced electron transfer between photosystem 2 via cross-linked redox hydrogels, Electroanalysis, 20 (2008) 1043-1047.

[9] A. Badura, T. Kothe, W. Schuhmann, M. Roegner, Wiring photosynthetic enzymes to electrodes, Energy Environ. Sci., 4 (2011) 3263-3274.

[10] Z. Du, H. Li, T. Gu, A state of the art review on microbial fuel cells: A promising technology for wastewater treatment and bioenergy, Biotechnol. Adv., 25 (2007) 464-482.

[11] B.E. Logan, B. Hamelers, R.A. Rozendal, U. Schrorder, J. Keller, S. Freguia, P. Aelterman, W. Verstraete, K. Rabaey, Microbial fuel cells: Methodology and technology, Environ. Sci. Technol., 40 (2006) 5181-5192.

[12] B. Rimbault, D. Esposito, D. Drapier, Y. Choquet, D. Stern, F.A. Wollman, Identification of the initiation codon for the atpb gene in chlamydomonas chloroplasts 
excludes translation of a precursor form of the beta subunit of the atp synthase, Mol. Gen. Genet., 264 (2000) 486-491.

[13] K. Maxwell, G.N. Johnson, Chlorophyll fluorescence - a practical guide, J. Exp. Bot., 51 (2000) 659-668.

[14] S. Izawa, Acceptors and donors for chloroplast electron transport, in: A. San Pietro (Ed.) Methods enzymol.1980, pp. P413-434.

[15] B. Genty, J.M. Briantais, N.R. Baker, The relationship between the quantum yield of photosynthetic electron-transport and quenching of chlorophyll fluorescence, Biochim. Biophys. Acta, 990 (1989) 87-92.

[16] R. Delosme, P. Joliot, J. Lavorel, Sur la complementarite de la fluorescence et de lemission doxygene pendant la periode dinduction de la photosynthese, C. R. Acad. Sci. Hebd. Seances Acad Sci. D, 249 (1959) 1409-1411.

[17] K.K. Karukstis, S.C. Boegeman, J.A. Fruetel, S.M. Gruber, M.H. Terris, Multivariateanalysis of photosystem-ii fluorescence quenching by substituted benzoquinones and naphthoquinones, Biochim. Biophys. Acta, 891 (1987) 256-264.

[18] K.K. Karukstis, S.M. Gruber, J.A. Fruetel, S.C. Boegeman, Quenching of chlorophyll fluorescence by substituted anthraquinones, Biochim. Biophys. Acta, 932 (1988) 84-90.

[19] L. Houille-Vernes, F. Rappaport, F.-A. Wollman, J. Alric, X. Johnson, Plastid terminal oxidase 2 (ptox2) is the major oxidase involved in chlororespiration in chlamydomonas, Proc. Natl. Acad. Sci. USA, 108 (2011) 20820-20825.

[20] F. Rappaport, B.A. Diner, Primary photochemistry and energetics leading to the oxidation of the (mn)4ca cluster and to the evolution of molecular oxygen in photosystem ii, Coord. Chem. Rev., 252 (2008) 259-272.

[21] M. Koblizek, J.D. Shih, S.I. Breitbart, E.C. Ratcliffe, Z.S. Kolber, C.N. Hunter, R.A. Niederman, Sequential assembly of photosynthetic units in rhodobacter sphaeroides as revealed by fast repetition rate analysis of variable bacteriochlorophyll a fluorescence, Biochim. Biophys. Acta, 1706 (2005) 220-231.

[22] F. Vanmieghem, K. Brettel, B. Hillmann, A. Kamlowski, A.W. Rutherford, E. Schlodder, Charge recombination reactions in photosystem-ii .1. Yields, recombination pathways, and kinetics of the primary pair, Biochemistry, 34 (1995) 4798-4813.

[23] A.W. Rutherford, A. Osyczka, F. Rappaport, Back-reactions, short-circuits, leaks and other energy wasteful reactions in biological electron transfer: Redox tuning to survive life in o-2, FEBS Lett., 586 (2012) 603-616. 
[24] D. Huppert, P.M. Rentzepis, G. Tollin, Picosecond kinetics of chlorophyll and chlorophyll-quinone solutions in ethanol, Biochim. Biophys. Acta, 440 (1976) 356-364.

[25] G.R. Seely, Energetics of electron-transfer reactions of chlorophyll and other compounds, Photochem. Photobiol., 27 (1978) 639-654.

[26] F. Rappaport, D. Beal, A. Joliot, P. Joliot, On the advantages of using green light to study fluorescence yield changes in leaves, Biochim. Biophys. Acta, 1767 (2007) 56-65. 